\title{
Investigating the Role of Activity-Travel Participation on Daily Travel Satisfaction in Bandung Metropolitan Area
}

\author{
Jeanly Syahputri \\ Civil Engineering Department \\ Parahyangan Catholic University \\ Bandung, Indonesia \\ jeanlysyahputri@gmail.com
}

\author{
Tri Basuki Joewono \\ Civil Engineering Department \\ Parahyangan Catholic University \\ Bandung, Indonesia \\ vftribas@unpar.ac.id
}

\author{
Dimas B.E. Dharmowijoyo \\ Civil and Environmental Engineering \\ Universiti Teknologi Petronas \\ Perak, Malaysia \\ dimas.bayu@utp.edu.my
}

\begin{abstract}
Relationship between daily travel satisfaction and individuals' travel behaviour has been explored by the number of studies. However, previous studies were rarely to examine the effect of daily activity in conjunction with travel participation on daily travel participation. Using general descriptive analysis, this present study expanded its focus on travel and satisfaction by investigating the role and its interconnected aspects of activity-travel participation and daily travel satisfaction in Bandung. The result showed that different levels of daily travel satisfaction may influence the potential activity-travel time-use.
\end{abstract}

Keywords: activity-travel participation, daily travel satisfaction, travel behavior

\section{INTRODUCTION}

Travel behaviour implies the concept of a 'trip' as the main unit of conventional measurement and analysis [1]. However, how the way an individual decides a single trip or daily trip is shaped by how the way an individual plan and schedules the daily activities, with whom and with what object the person needs to meet, in where the activities are undertaken, and what regulation shape the activities and travels. It means that a travel decision is an effect of complex interdependencies among planned/scheduled and undertaken activities, interdependencies between activities and travels itself, the possibility of activity locations around the individuals, and the shape of regulation. Recently, the activity-based human approach is utilized to replace this simplistic approach to travel behaviour [2] Understanding how people define and decide their daily activity-travel participation can help to provide insight understanding and insight proposed policies to achieve a particular goal. Understanding people continuous path through space and time whereby how people perform activities and travels, with whom, what objects and in which location she/he meets, and what regulation influences their daily life, reveals what policy that can or cannot achieve a particular goal. Individuals' decision-making process is complex as a result of the complex interaction of people's constraints, needs, and possible resources through time and space $[3,4,5]$.

Travel is the activity that reports low emotional well-being $[6,7,4]$. Therefore, researchers try to find a way how to improve the travel satisfaction or travel experience. Undertaking a particular type of passive leisure such as online and/or offline socializing shows a better impact on travel satisfaction $[8,9,10]$. Friman et al. [11] investigated the daily travel experience using cross-sectional observations explained by socio-demographic and travel mode variables. However, Friman et al. [11] did not include other spatiotemporal variables such as the time-use and activity participation and built environment conditions as the predictors of daily travel experience. This study tries to fill the research gap on how the influence of various spatiotemporal variables on daily travel satisfaction. The focus on satisfaction with travel and daily routines is relevant both from a viewpoint of the implications of policies for well-being, but also since travel that is experienced as more satisfactory is more likely to be sustained over longer period [12].

\section{LITERATURE REVIEW}

Studies of travel satisfaction have recently received increasing attention in the field of transportation [13]. Early work in the area of satisfaction suggested that satisfaction was a result of proceeding from the evaluation based on consumer's expectations of the service/product and the experience [14]. The study of travel satisfaction based on travellers' judgment (e.g Friman [11], Ettema [12], Ye \& Titheridge [13]) has only recently been discussed in transportation research [15]. For example, Ettema et al. [16] built a theoretical framework introducing subjective wellbeing (SWB) as a concept that complements other methods of assessing how people evaluate transportation services.

Essentially, the studies of travel satisfaction would provide useful detailed information for a broad range of policy decisions [17] and support urban planners to create transport strategies that improve subjective well-being or helping transportation providers to their service provision evaluation [15]. For example, it has been recognized that time pressure is a significant factor affecting travel satisfaction and, for that reason, some recommendations such as changing the opening hours of facilities and public transportation nodes might have an impact on travel satisfaction [12]. Moreover, early study of time and space prism concept [3] has discussed time pressure as one of three individuals' time and space constraints (capability, coupling, and authority). Hagerstand [3] defined coupling constraints as individuals' limitations to certain decisions to be in a specific place in a specific time. This concept also 
initially introduced for social scientists and developed in the field of activity-based human's approaches on travel behaviour study.

Activity-based travel analysis approaches analysed travel from a theoretical perspective that takes into a description of the demand for activity participation, interrelationships among trips and interactions among household members [18]. Hence, the implication using the human activity-based approach on travel behaviour has consequence in the development of studies its supporting variables such as socio-demographic, land use, and built environment as part of individuals' travel characteristics have followed [19, 20, $21,22]$.

\section{METHODS}

There are varieties of resources that have been used on behalf of this research such as literature review from journals, books, articles, as well as online researches. This study involved a multi-dimensional dataset consisted of the socio-demographics, built environment, activity-travel participation (ATP) and daily travel satisfaction (DTS). This study is completed using the 2013 Bandung Metropolitan Area (BMA dataset). The dataset was collected in 2013 throughout 21 consecutive days from 191 households with a total of 732 members at the age above seven all over the Bandung Metropolitan Area (BMA) which initially part of the study of Dharmowijoyo [23].

ATP data is collected by activity diary survey questions. This survey was divided into 96 time-slices in one day with 15 minutes' interval. The activities were then divided into travel participation and six activity classifications which differ between in-home and out-of-home activity participation, as well as, degree of space and time fixity which are divided into three (mandatory, maintenance, leisure). Meanwhile, DTS data were collected based on five questions of travel satisfaction statements without focusing on particular travel mode as suggested by Bergstad [24]. The five questions ranging from 1 (disagree) to 7 (agree) are: "I am completely satisfied with my last week daily travel"; "My travel facilitates my last week daily life"; "When I think of my last week daily travel, the positive aspects outweigh the negative"; "I do not want to change anything regarding my last week daily travel" and "My last week daily travel makes me feel good". Afterward, the five measurements of DTS will be utilized with factor analysis into the respondents' DTS score. Lastly, the variables of activity-travel participation and daily travel satisfaction are analysed using general descriptive analysis.

\section{ANALYSIS RESULTS AND DISCUSSION}

\section{A. Description of Respondent's Activity-Travel Participation (ATP)}

The respondent's average activity-travel time use allocation across the week can be seen in TABLE I and Fig. 1 In terms of activities category, the duration in which mandatory activities are undertaken roughly the entirely of both leisure activities and maintenance activities time allocation. The trend of activities across the week differs based on its classification. Contrary to out-of-home mandatory activity, it is shown that there was increasing inhome activities allocation for all mandatory, maintenance, and leisure activities at the weekend. Moreover, significant changes in activity allocation across the weekdays are not shown.

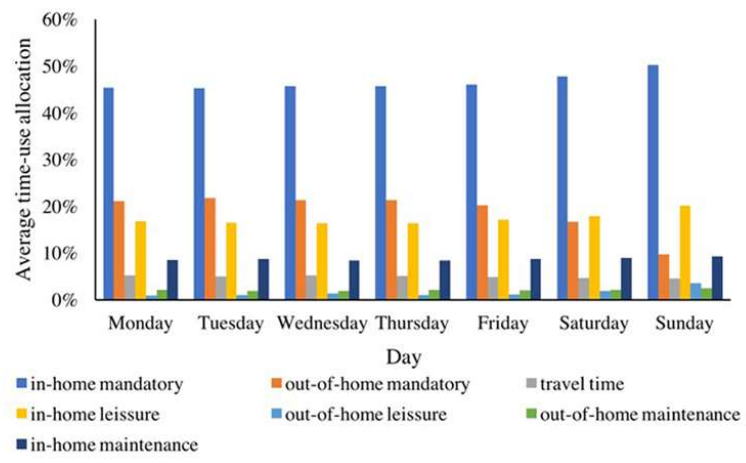

Fig. 1. Individual's activity-travel time use.

Regarding travel participation, there are not found any substantial variations in the duration of travel across the week. Meanwhile, it is shown that respondents are generally undertaken the longest travel time on Friday. Similarly, Friday has the highest rate of the number of trips as well as, the series of trips with the starting and ending locations at home (trip chains).

TABLE I. DESCRIPTION OF RESPONDENT'S TRIP ENGAGEMENT AND TRAVEL TIME SPENT

\begin{tabular}{|l|l|l|}
\hline Characteristics & \multicolumn{1}{|c|}{ Day } & Percentage/mean \\
\hline \multirow{3}{*}{$\begin{array}{l}\text { Number of } \\
\text { trips/day }\end{array}$} & Monday to Thursday & 2.52 \\
\cline { 2 - 3 } & Friday & 2.76 \\
\cline { 2 - 3 } & Weekend & 2.29 \\
\hline \multirow{3}{*}{$\begin{array}{l}\text { Number of trip } \\
\text { chains/day }\end{array}$} & Monday to Thursday & 1.20 \\
\cline { 2 - 3 } & Friday & 1.31 \\
\cline { 2 - 3 } & Weekend & 1.08 \\
\hline \multirow{3}{*}{$\begin{array}{l}\text { Total travel time } \\
\text { spent (minutes) }\end{array}$} & Monday to Thursday & $73.97(5.14 \%)^{\mathrm{a}}$ \\
\cline { 2 - 3 } & Friday & $75.76(5.26 \%)^{\mathrm{a}}$ \\
\cline { 2 - 3 } & Weekend & $69.35(4.82 \%)^{\mathrm{a}}$ \\
\hline \multirow{2}{*}{ The brackets show the average time spent on travel and in-home and out-of-home }
\end{tabular}
activity.

B. Description of Respondents' Daily Travel Satisfaction (DTS)

As mentioned before, the five values from DTS related questions are combined into a single score formulated by factor analysis. The Kaiser Meyer-Olkin measure of sampling adequacy scored higher than 0.8 or 0.847 to be exact. This suggested that the total of partial correlation was relatively small to the total of the whole population. Moreover, the value Bartlett's Sphericity Test was below 0.5 which shown significance, as well as, the variance value (0.74) exceeds 0.7 indicates that the daily travel satisfaction score was acknowledged for further exploration. All of the DTS latent variables are strongly associated with the factor score of DTS. Moreover, the DTS scores showed an average slightly negative value with kurtosis towards positive value. However, most respondents have a slightly positive factor score. This indicates a larger share of respondents who were neither highly satisfied nor highly dissatisfied with their daily travel. 


\section{Interaction Between ATP and DTS}

Fig. 2, Fig. 3 and Fig. 4 show the activity-travel time-use allocation based on respondents who have the highest travel duration on Monday-Thursday, Friday and Saturday-Sunday respectively. There are four-bar in each figure which represents different quartile of respondents' daily travel satisfaction score. The first quartile represents a group of respondents who have the highest level of DTS. The activity-travel time allocations are displayed based on its classification. Meanwhile, respondents who viewed their daily travel poorly are categorized in the fourth quartile. It is expected that the days across the week in which individuals spent their most travel time are able to describe its impact on the level of DTS by the composition of time use allocation.

Despite significant longer in-home maintenance activities in the lowest level of DTS in Fig. 2, Fig. 3 which also represent respondents who travel the most on weekdays, generally show similar patterns yet the slightly different proportion of activities. In those figures, higher out-of-home mandatory and travel time allocation indicates better satisfaction. Meanwhile, in Fig. 4, a higher level of DTS indicates increases in in-home maintenance time allocation. Similar to Fig. 3, respondents who undertaken more in-home leisure also indicate a higher level of DTS. Furthermore, there are not found significant variations of activity-travel time use with different days where travel most undertaken.

In terms of different days in which respondents spent their most travel time, it is found that respondents who travel the most in weekdays, spend longer travel time in a day than those on the weekend. Additionally, respondents who spend most of their travel time on the weekend also spend more time in doing in-home mandatory and in-home maintenance activity. On the contrary of higher allocation in out-of-home mandatory activity is shown in those with longer travel time on weekdays. This shows resemblance with workers who are commonly doing their job as one of the mandatory activities outside their houses, act as regular commuters who travel the most on weekdays.

Considering the overall interaction between day-to-day ATP and DTS, different interaction between activity patterns based on what day was respondents travel the most are shown. Respondents who travel the most on weekdays and allocate more time out-of-home mandatory activity, value their travel more positively. As mentioned above, workers and students who generally undertaken out-of-home mandatory more than others and frequently commute on weekdays and could be classified as regular commuters may have some adjustment to their routine. Regular commuters who have adjusted to their trip may have little need for multi-purpose and multi-stop travel experienced due to their repetitive trip may be one of the explanations to this [24]. Additionally, Fig. 2, Fig. 3 and Fig. 4 shows a higher level of DTS indicates less time in-home mandatory activity. However, there were no substantial differences regarding leisure activity time-use neither vary between different levels of DTS nor across the days of the week where respondents travel the most.
Focusing on the interaction between DTS and travel time shows a composite measure of day-to-day travel time based on respondents' level of DTS. In Fig.5, respondents are classified into two groups. The first group represents respondents who value their daily travel positively. The respondents in this group have a daily travel satisfaction factor score above zero. Meanwhile, the respondents who are part of the second group have daily travel satisfaction factor score below zero which indicate dissatisfaction in their daily travel.

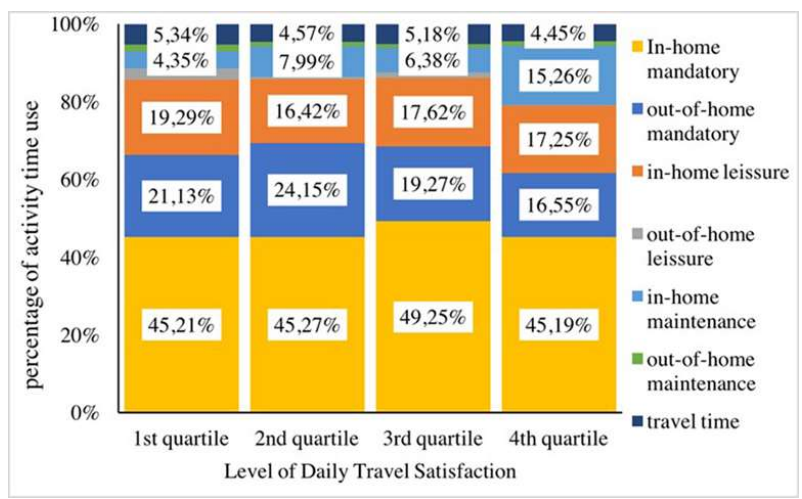

Fig. 2. Activity-travel time-use of respondents with travel time mode on Monday-Thursday.

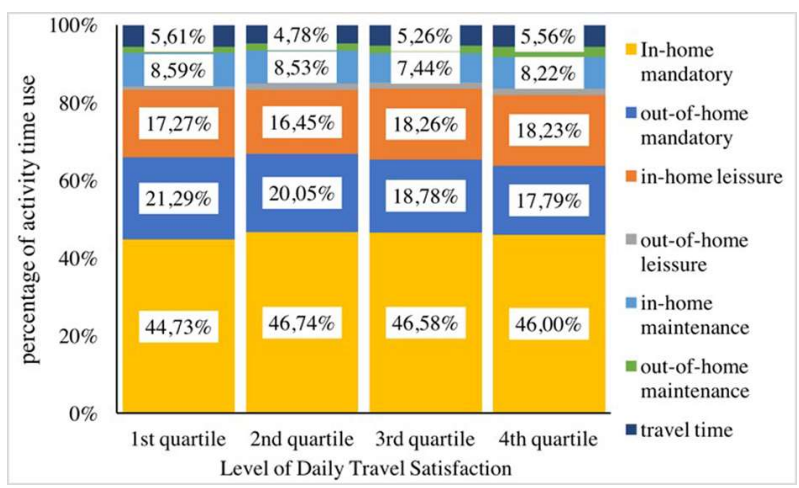

Fig. 3. Activity-travel time-use of respondents with travel time mode on Friday.

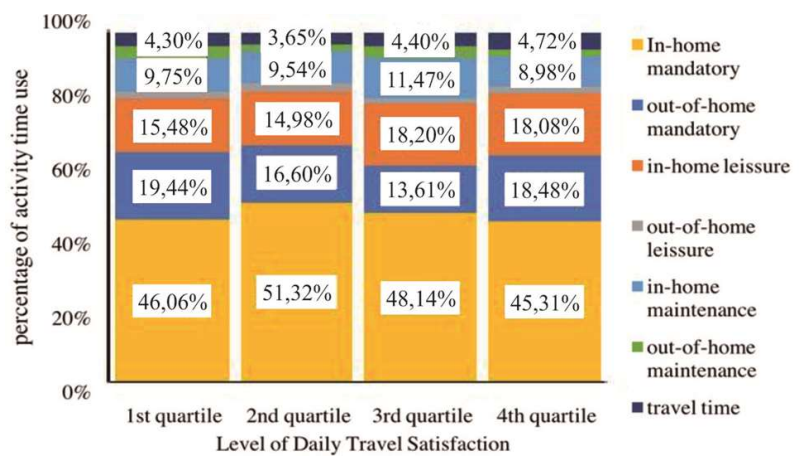

Fig. 4. Activity-travel time-use of respondents with travel time mode on weekend.

In Fig. 5 It is shown that respondents who have longer travel time showed dissatisfaction in their daily. This shown resemblance with Olsson [25] which measured increases in the commuting duration of both to and from work decreases 
travel satisfaction. This measure also showed similarities with, previous founding of travel satisfaction study [9], where those who have relatively longer trips on weekdays were more satisfied with their daily travel. In another word, those who relatively travel more on the weekend showed dissatisfaction. Consider that BMA reached its peak times at weekends, this also supported the result of a study [26] which observed that traveling outside of peak periods positively satisfied. The crowdedness, which increased in peak periods, suggested to caused travel dissatisfaction.

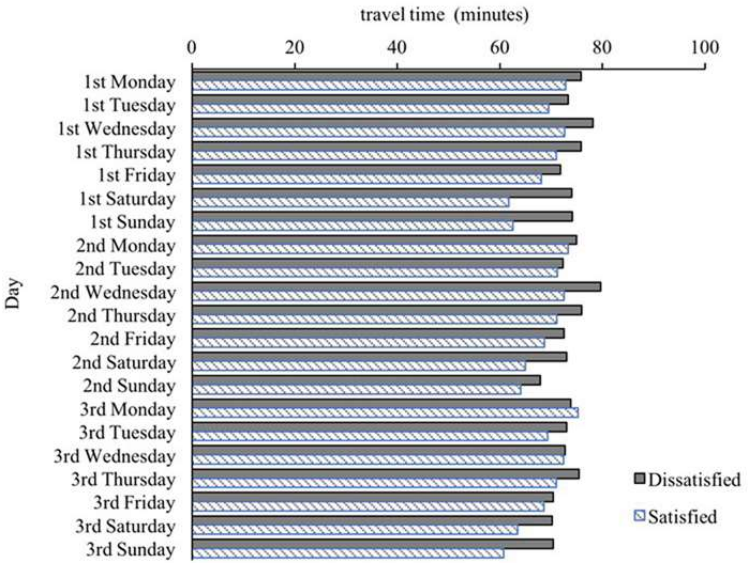

Fig. 5. Individual's activity-travel time use Activity-travel time-use of respondents with travel mode on weekend.

\section{CONCLUSIONS}

This study showed a description of the role of activitytravel participation and its supporting parameters to daily travel satisfaction. The BMA dataset's unexplored variable of daily travel satisfaction has initially examined and consequently showed a potential result. It is shown that DTS differs based on individuals' travel duration and the day in which travel is undertaken. Those who commute in a shorter duration and travel more on weekdays value their daily travel more positively. Moreover, a higher level of daily travel satisfaction also shown in individuals who undertake a more out-of-home mandatory activity. In other words, this study found that besides of to improve the travel attributes itself, the subjective views on daily travel have potentials for wider purposes, in this case, to describe the potential of individuals' activity performed.

\section{REFERENCES}

[1] P. M. Jones, "Household Organisation and Travel Behaviour," Gender, Transport and Employment, vol. 3, pp. 46-74, 1989.

[2] P. M. Jones, "A New Approach to Understanding Travel Behaviour and its Implication for Transportation Planning," 1983.

[3] T. Hägerstrand, "What About People in Regional Science?," Papers of the Regional Science Association, vol. 24, no. 1, pp. 6-21, 1970.

[4] T. Schwanen and D. Wang, "Well-being, Context, and Everyday Activities in Space and Time," Annals of the Association of American Geographers, vol. 104, no. 4, pp. 833-851, 2014.

[5] D. B. Dharmowijoyo, Y. O. Susilo, A. Karlström and L. S. Adiredja, "Collecting a Multi-Dimensional Three-Weeks Household Time-Use and Activity Diary in the Bandung Metropolitan Area, Indonesia," Transportation Research Part A, vol. 80, pp. 231-246, 2015.

[6] D. Kahneman, A. B Krueger, D. Schkade, N. Schwarz and A. Stone, "A Survey Method for Characterizing Daily Life Experience: The
Day Reconstruction Method," science, vol. 306, no. 1, pp. 17761780,2004

[7] M. Friman, "Implementing Quality Improvements in Public Transport," Journal of Public Transportation, vol. 7, no. 4, pp. 49-65, 2004

[8] D. Ettema, M. Friman, T. Gärling and L. E. Olsson, "How inVehicle Activities Affect Work Commuters' Satisfaction with Public Transport," Journal of Transport Geography, vol. 24, no. 24, pp. 215-222, 2012.

[9] S. Rasouli and H. Timmermans, "Accounting for Heterogeneity in Travel Episode Satisfaction Using a Random Parameters Panel Effects Regression Model," Procedia Environmental Sciences, vol. 22, no. 1, pp. 35-42, 2014.

[10] T. B. Joewono, A. K. M. Tarigan and M. Rizki, "Segmentation, Classification, and Determinants of In-Store Shopping Activity and Travel Behaviour in the Digitalisation Era: The Context of a Developing Country," Sustainability, vol. 11, no. 6, pp. 1591-1614, 2019.

[11] M. Friman, T. Gärlingb, D. Ettemac and L. E. Olssona, "How Does Travel Affect Emotional well-being and Life Satisfaction?" Transportation Research Part A, vol. 106, pp. 170-180, 2017.

[12] D. Ettema, T. Gärling, L. Eriksson, M. Friman, L. E. Olsson and S. Fujii, "Satisfaction with travel and subjective well-being: Development and Test of a Measurement Tool," Transportation Research Part F, vol. 14, no. 3, pp. 167-175, 2011.

[13] R. Ye and H. Titheridge, "Satisfaction with the Commute: The Role of Travel Mode Choice, Built Environment and Attitudes," Transportation Research Part D, vol. 43, no. 5, pp. 771-796, 2016.

[14] R. L. Oliver, "A Cognitive Model of the Antecedents and Consequences of Satisfaction Decisions," Journal of Marketing Research, vol. 17, no. 4, pp. 460-469, 1980.

[15] Y. Gao, Travel Satisfaction and Subjective well-being: A Behavioral Modeling Perspective, Eindhoven: Technische Universiteit Eindhoven, 2018.

[16] D. Ettema, T. Gärling, L. E. Olsson and Margareta Friman, "Out-ofhome Activities, Daily Travel, and Subjective well-being," Transportation Research Part A, vol. 44, no. 9, pp. 723-732, 2010.

[17] M. Friman, S. Fujii, D. Ettema, T. Gärling and L. E. Olsson, "Psychometric Analysis of the Satisfaction with Travel Scale," Transportation Research Part A, vol. 48, pp. 132-145, 2013.

[18] C.-H. Wen and F. S. Koppelman, "A Conceptual and Methdological Framework for the Generation of Activity-Travel Patterns," Transportation, vol. 27, no. 1, pp. 5-23, 2000.

[19] J. D. Vos, B. Derudder and F. Witlox, "Including Travel Satisfaction in Travel Behaviour-Land Use Interaction Research," in Adaptive mobility: A New Policy and Research Agenda on Mobility in Horizontal Metropolisesadaptive Mobility: A New Policy and Research Agenda on Mobility in Horizontal Metropolises, Ghent, In Planning, 2015, pp. 67-84.

[20] Y.-J. Chen, "Structural Analysis on Activity-travel Patterns, Travel Demand, Socio-demographics, and Urban Form: Evidence from Cleveland Metropolitan Area,", Cleveland, 2017.

[21] H. Kang and D. M. Scott, "Exploring day-to-day Variability in Time use for Household Members," Transportation Research, vol. Part A, no. 44, pp. 609-619, 2010.

[22] T. Schwanen, M.-P. Kwan and F. Ren, "How fixed is How Fixed is Fixed? Gendered Rigidity of Space-Time Constraints and Geographies of Everyday Activities," Geoforum, vol. 38, no. 1, pp. 2109-2121, 2008.

[23] D. B. E. Dharmowijoyo, "The Complexity and Variability of Individuals' Activity-Travel Patterns in Indonesia," Transportation, vol. 45, no. 1, pp. 177-204, 2016.

[24] J. C. Bergstad, A. Gamble, T. G. rling, O. Hagman, M. Polk, D. Ettema, M. Friman and L. E. Olsson, "Subjective well-being Related to Satisfaction with Daily Travel," Karlstad University Studies, Karlstad, 2011. 
[25] L. E. Olsson, T. G. rling, D. Ettema, M. Friman and S. Fujii, "Happiness and Satisfaction with Work Commute," Soc Indic Res, vol. 111, no. 1, pp. 255-263, 2013.

[26] C. Pineda and B. M. Lira, "Travel Time Savings Perception and Well-Being through Public Transport Projects: The Case of Metro de
Santiago," urban science, vol. 3, no. 35, pp. 1-22, 2019. 